\title{
MOOCs and SPOCs: Evolution and Inheritance of Online Education
}

\author{
Li Lin \\ (College of Education, Sichuan University of Arts and Science, Dazhou, Sichuan, 625000)
}

\begin{abstract}
The rise of MOOCs is strongly influencing the course teaching at colleges and universities. However, the development of the course is also accompanies by some doubts. As the inheritance ad development of MOOCs, SPOCs reestablished the development of online education. This paper first analyzes problems during the course of developing MOOCs as well as innovation and development of SPOCs, and then provides references for the development of online education through comparing and analyzing MOOCs and SPOCs.
\end{abstract}

Keywords-MOOCs; SPOCs; doubt; evolution; inheritance

With the emergence and rapid development of MOOC all over China and the promotion of various types of MOOC platforms and corresponding promotion activities, MOOC is becoming increasingly popular in China. Meanwhile, more and more people are concerned about another problem: where is the future of MOOC?

\section{I. "TAKE A GLIMPSE" INTO THE MOOCS ERA: THE SOCIETY's DOUBTS ABOUT MOOC}

MOOC, a massive online open course, was proposed by the Canadian scholar Dave, a Canadian scholar, and Blaine Alexander, who was well known for the course of "Introduction to artificial intelligence" at the Stanford University in 2011. 2012 is known as the first year of the first year of the MOOC class, Mu class outbreak. The United States launched the three MOOC class platforms: Udacity platform, edX platform, Coursera platform, Stanford University, MIT, Harvard and other more than 40 public universities in the U.S. In 2013, China's colleges and universities has announced to join the platform above, 5 August Tsinghua, Peking University join EDX platform, July, Fudan University, Shanghai Jiaotong University join Coursera platform. The rise of MOOC class caused the attention of the universities, but also brought pressure and challenge to the education.

\section{A. Doubt, MOOCs cannot Coexist with Teachers}

MOOC is the expansion of quality education resources in the world, the promotion in the world, first of all the less developed areas of the teachers feel the pressure to survive, the possibility of the students' autonomy is increased, and the relationship between the ordinary school weakened, so that a large number of teachers lose their job. MOOCS itself also has memory, the teacher of an input can be used multiple times, due to interactive learning network discussing the characteristics, in the future will have more graduate students to participate in the discussion, eliminating activities, will effectively promote the dynamic course content increased, and function of instructors and teaching assistants will degenerate and blanking. In addition, some universities are trying to use MOOCs to replace part or all of the existing curriculum to promote the upgrading of teaching resources. But some people are worried that this will not be the school, reduce the teaching cost a tricky behavior.

Based on the study of the network, in the group discussion and the communication between the teachers and students is not carried out, although there are a lot of social software, but still can not completely replace the face to face communication activities. Face to face communication between teachers and students, in addition to the discussion of subject knowledge and the influence of teacher's personality charm, can effectively achieve the effectiveness of teaching and educating people. In addition, face to face communication from the horizontal perspective, due to the impact of context, material environment, with the exchange of content of the divergence. From the vertical perspective, the number of participating in the face-to-face communication is controllable, and the same topic of communication depth is deeper than the network discussion. Network is discussed, macro, number, discussed the content and number of wide coverage, but from the micro, individual a specific communication topic comparison of minority, it is easy to be "refreshed" or "bottoming out" that discussing difficult to carry out.

New York Times published in 2003, "free open online courses", is a detailed discussion of the problems of the MOOC era, which refers to the three major problems of MOOC teaching, the first is the high dropout rate, there is no doubt that MOOC brings a lot of students in the course, but also produced a large number of students to give up the curriculum. Second courses have low rates of participation in online learning courses, most of the students because of various reasons not to complete the final assessment. Third is the quality of the course itself is not a strict audit, the quality of the course is questioned.

\section{B. Doubt Three: MOOCs Teaching Can Reduce Teachers' Energy in On-Campus Classroom Teaching}

At present, in the domestic each MOOC platform opened MOOCS most of the teachers are not the internationally renowned experts, academic strongman, some people questioned commenced teaching ability, at the same time that the experts, academic strongman, does not offer MOOCS is afraid of own research and campus classroom teaching effect. MOOCS opened in tens of thousands of students to submit a job, need the teacher's marking, tens of thousands of small talk and need to attention and reply. Teacher's effort will be invested to online, offline course any further strengthened, whether the teachers there is spare capacity, curriculum reform. 
In addition, doubts about MOOC also include reducing the diversity of teachers and teaching methods in MOOC. MOOCs can lead the entire class so that the trend of global education integration is increasingly obvious.

\section{II. "EVOLUTION AND INHERITANCE" OF THE POST-MOOCS ERA: THE BIRTH OF SPOC IS THE RESPONSE TO DOUBTS}

MOOC is a kind of new teaching technology, although its teaching form and method is based on the concept of the learning of the Unicom, and use the existing technology and means to effectively integrate. But it focuses on the potential impact of education, the students' learning behavior in a comprehensive record, the students learning behavior of the big data to study the potential impact of education, to provide data services for new educational reform.

Professor Armando Fox at the University of California, Berkeley proposed the MOOC with the matching SPOC (Small Private Online Course), in which Small and Massive, Private and Open. Small emphasize the course from dozens to hundreds of (generally no more than 500 people), Private stressed that all the students to pass the course restrictive conditions. SPOC students mainly from college students and some online students. For college students is a combination of classroom teaching and online teaching model of blended learning. On campus, the use of MOOCs lecture video or other teaching materials to flip the classroom teaching. Geared to the needs of online students, SPOC by setting the course of the previous conditions, students from all students to apply for, choose qualified learners to teaching. The selected students have the full mental preparation, to pay enough time and strength to keep learning, fulfilling the specified price discussion and homework, to ensure the learning effect.

Currently, in Berkeley, California, Harvard, MIT and other universities during the SPOC Teaching. Specific embodiments have, for MOOC platform enhanced with small class management, team learning, enhance the students' individualized learning full attention, and to further explore the sustainable development model. Which authorized the use of MIT San Jose State University in California, "circuit theory" MOOCs teaching. In the teaching process, teachers use SPOC platform to disseminate excellent teaching content, and through automatic test system platform for evaluation of students, students and teachers can complete all aspects of the experiment at the same time. Students in this SPOC, the students than to accept the traditional teaching methods and teaching materials, students are more likely to get better school results. The course pass rate increased from $59 \%$ to $91 \%$.

With these tries and reforms, the international "Financial Times" dictionary will SPOC deemed MOOC mode of competition, the American scholar Rolf • Hoffman believes SPOC $=$ classroom + MOOC, indicating SPOC has online education and classroom teaching good fused together, and Rolf $\bullet$ Hoffman believes SPOC has replaced MOOCs, online education is reshaping the new ecology. SPOC creation, complement the role of the teacher in the teaching activities MOOC, teachers return to the classroom, from online back to school, teaching activities again become planners, implementers and participants. MOOCs into the teaching activities of resources and the exchange and evaluation platform, no longer all teaching. Effective response to social question MOOC's.

\section{A. Essence of SPOC}

After the birth of MOOC, SPOC is a new teaching model used by teachers with MOOC resources in campus classrooms, and its core values are still the classroom, whether it is for students in a mixed mode of teaching, or teaching activities based on the network, is nothing less than the classroom teaching resources to expand, or is part of the teaching activities transfer to carry the network. But the core component of the course is not change, it is still teacher to design and organize the implementation of teaching activities. Teaching each element is controllable, from the student scale, learning progress, learning, motivation to maintain, communication topics are within a certain range. Moreover, small-scale SPOC Courses, that can be achieved online, offline activities simultaneously launched, teachers of energy, the geographical scope of the students can be protected.

SPOC redefines the role of teachers, teachers who control again become the curriculum, before class, the teacher is the setter integrator curriculum resources, curriculum technology. Need not be taught by lectures in the video, but in accordance with the needs of students to the corresponding adjustment of teaching resources. In the teaching process, teachers play a student guide and mentor role is to be a scholar to explain the video lectures, leading the students to identify problems, guiding students to solve problems. After class, the teacher is the evaluator, have face to face communication, communication or through the network, allowing teachers to most students have an intuitive understanding of the evaluation process, a rational fraction also qualitative sensibility of students three-dimensional evaluation.

The biggest advantage SPOC platform is to give students a more realistic body experience, students can participate more realistic in the learning process, to better mobilize the enthusiasm of students, improve learning courses. SPOC is a student organization can form a class, which will help supervise the students, at the same time, foster collaboration between awareness and ability of students. Therefore, East China Normal University professor Zhu Zhiting has translated SPOC as "private broadcast lesson".

\section{B. SPOC is the Evolution and Inheritance of MOOC}

\section{1) $\mathrm{SPOC}$ is the Inheritance of MOOC}

At the beginning of the birth of MOOC, the design of the video resources, the design of the precision test, the study of the big data and the design of the wide range of China Unicom. SPOC will be the perfect reference and absorption of these practices, SPOC is based on the MOOC platform derived. The learning analysis based on big data is still an important motivation of the teachers in the information environment, trying to find the students in the learning process of the habits, how to learn to become more effective is the direction of every teacher to pursue. Can even understand SPOC is actually also commenced at the University and MOOC, the operators focus on University students. 
With small number of students, SPOCs can pay full attention to each student's learning process, combined with personal learning portfolios, evaluate the growth of the students Section of the man-machine combination, to avoid the machine itself unreasonable evaluation of the lack of humanization and evaluation system while maintaining the focus on the external motivation to help students, teachers, students care, help for students alone, encountered problems in students in the process of solving the network face to face communication with teachers and other students to discuss and diverse solving the channel, while the network is solved SPOC students communicated with the outside window on, let SPOC's small as possible confined to small number, and curriculum resources are massive.

SPOC operating costs are relatively low. Throughout the course of the construction, the MOOC program has completed the production of related video, animation, testing, SPOC is mainly used in the scope of these resources, the scope of the new resources are relatively small, the operating platform is also MOOC platform. From the current creation of SPOC institutions, basically no additional cost in the operation process.

2) SPOC's Transcendence of MOOC

MOOC and the various network learning models before, only the creation of their own innovation and all aspects of the study to help. But in fact, all of the network teaching mode has the lack of face-to-face exchange of ideas in the collision of sparks, cannot really take care of every student, it is difficult to achieve individual guidance. To the network learning mode in the face of the face of the exchange, in fact, has been to learn from their own network in the hybrid learning. Finally return to the school teaching, or the beam of tall buildings.

\section{III. “UPGRADE” IN THE SPOC ERA: HOW SPOC PROGRESSES IN DOUBTS}

SPOC era is considered "private broadcast class" era, SPOC number of students and learning conditions are limited. SPOC era to break through the question, the tree of the university teaching situation, the article think should be from the following three aspects.

\section{A. Pay Attention to the Interaction between Teachers and Students}

SPOC encourages a variety of ways to interact. A change of the zero interaction of the traditional network open class, SPOC will interact as an important aspect of the course learning behavior to show. The main interactive methods of SPOC are: real time communication, forum and work. During the commencement, course website every day have a fixed time tutor online, for students to provide smooth learning and exchange opportunities, the assistant will be in the forum for real-time and non-real time communication. Curriculum also encourages learners to use the forum, Wiki, and other ways to interact with learners. In short, in the process of learning, to create a strong learning atmosphere of the traditional classroom, the learning environment to influence and change the learning behavior of learners.

\section{B. Pay Attention to the Quality of SPOC Curriculum Resources}

Curriculum resources are the first step to lead students to the course, and it is the beginning of the students' contact course. The curriculum resources of SPOC are diversified in form and appear in the form of fragmentation. The learning resources provided by SPOC include: teaching video, virtual experiment, exercises set, assessment, reading materials, discussing and testing, etc. The presentation form of the course is also based on knowledge, such as the length of the video, rather than the traditional class as a unit. The submission of assignments has time limit, and if you need to obtain a course certificate, you need to ensure that the relevant work within the specified time. Fragmentation of the resources, is conducive to the use of the time to learn to learn.

\section{Pay Attention to Curriculum Resource Management}

SPOC curriculum resources management should implement unified management, including the opening time of the course, the course to open the way, the course of the way two aspects. Commencement time. According to the concept of the SPOC, course opened set the time period, the specific time according to the curriculum and the employing units and the negotiation and decide, such as 1 month, 2 months, range. Setting time for the course is to guarantee the quality of the course. Course completion of the certification by the employing units. Such as obtaining a certificate of completion to the appropriate incentives, etc.

\section{CONCLUSION}

As the continuation and innovation of MOOC, SPOC can also affect the development and innovation of online teaching. However we should think about how SPOC can promote the development of online education in the "post-MOOC" era. Similarly, SPOC cannot be the ultimate educational form, but there will be the "post-SPOC" era. During the process of its development, we should also think about how to establish sound development of teaching so that online education can well develop.

\section{REFERENCES}

[1] Zheng Qi, Yang Zhuyun. SPOC: Integration and Innovation Combined with College Teaching $[\mathrm{J}]$. Physics and Engineering, 2014(1).

[2] Xu Wei, Jia Yongzheng, [U.S.] Armando Fawkes, [U.S.] David Paterson. From MOOC to SPOC - Academic Dialogue of MOOC Practice Based on the University of California at Berkeley and Tsinghua University [J]. Modern Distance Education Research, 2014(4).

[3] Kang Yeqin. "Post-MOOC Era" of Online Education - Analysis of SPOC [J]. Educational Research of Tsinghua University, 2014(2).

[4]Will Oremus. Forget MOOCs[EB/OL]. [2013-09-18]. http://www.slate.com/articles/technology/technology/2013/09/spocs small private online classes may be better than moocs.html.

Fund Project: Key Research Base Project of Humanities and Social Science at Sichuan Educational Department (SLQ014C-14)

Introduction to the Author: Li Lin (1982-), male, Tongjiang, Sichuan, Lecturer, Master, engaged in online education research 